\title{
Contribution to the study of collagen degradation
}

\section{Contribuição ao estudo da degradação do colágeno}

\author{
Andrea Cavalcanti \\ Aryon A. Barbosa Jr. \\ Zilton A. Andrade
}

\begin{abstract}
key words abstract
Collagen degradation

The rate and morphology of collagen degradation were comparatively analyzed in rats with

$\mathrm{CCl}_{4}$-induced fibrosis

"early" and "late" carbon tetrachloride-induced hepatic fibrosis, during three different

Hepatic cirrhosis

periods after discontinuation of the drug. Treatment with $\mathrm{CCl}_{4}$ lasted for eight weeks for the

group of early fibrosis and 12 weeks for the late fibrosis group. Fibrosis gradually

disappeared, but when quantitative methods were applied, the amount of collagen

degradation and removal in early and late fibrosis did not reach statistical significance. The

light microscope and ultrastructural changes were also qualitatively similar in both cases.

Probably some long-lasting effects to the liver, induced by the drug, prevented early hepatic

fibrosis from undergoing the characteristic ultrastructural changes seen during "acute"

collagen degradation, as compared to other experimental models of hepatic fibrosis, after the

causal agent is totally removed. Present findings suggest that not only the age of fibrosis but

also the overall damage inflicted to the organ are limiting factors in the process of collagen

degradation and removal.
\end{abstract}

O grau e a morfologia da degradação do colágeno foram comparativamente analisados em ratos com fibrose hepática recente (tratamento de oito semanas com tetracloreto de carbono) e tardia (igual tratamento por 12 semanas), e acompanhados após a suspensão da administração da droga. O desaparecimento da fibrose (quando quantitativamente avaliada) foi gradual e semelhante para ambos os grupos. As modificações vistas à microscopia de luz e ao microscópio eletrônico foram também semelhantes. Estes resultados inesperadamente negativos diferem de outros modelos de fibrose hepática e sugerem que o grau de agressão ao parênquima hepático

seja um fator limitante da degradação da fibrose que se segue à remoção do agente causal. Assim sendo, não apenas a idade da fibrose, mas o estado geral de alteração do órgão atingido unitermos

por $\mathrm{CCl}_{4}$

Cirrose hepática

influenciam a degradação e remoção do colágeno.

\section{Introduction}

Acute collagen degradation is said to occur when the cause of a recently installed fibrosis is removed. Fibrosis is then usually resorbed in less than a month, presenting an ultrastructural picture dominated by two main changes: extra-cellular collagen breakdown and internalization of collagen fragments, with strong evidences of metalloproteinase activity $(3,11,13,16)$.
On the other hand, chronic collagen degradation occurs in long-standing fibrosis, takes months or years to be noticeable and exhibits two different ultrastructural features: focal lytic and focal electron-dense collagen changes $(1,4,5)$, with the expression of metalloproteinases and TIMP being not histochemically demonstrable (12).
Curso de pós-graduação em Medicina Interna - Universidade Federal da Bahia; Centro de Pesquisas Conçalo Moniz (Fiocruz), Salvador (BA), Brasil. 
Progressive removal of excess fibrous tissue, revealed by morphologic and/or biochemical evidences of collagen degradation, has long been recognized to occur in both physiological and pathological conditions $(15,17)$. The morphology of collagen degradation markedly differs when recent and old fibroses are in the process of being removed, as observed in experimental hepatic schistosomiasis of mice $(3,4)$ and during the involution of the Seyle's inflammatory pouch in rats (11). These differences, also observed on hepatosplenic schistosomiasis of man $(1,5,12)$, have led to the suggestion that the mechanisms operating in acute and chronic collagen degradation may also differ, since morphology and function are closely related. Most experimental models used for the study of extra-cellular matrix degradation (metamorphosis of the tadpole tail, the carrageenin granuloma, involution of the pregnant rat uterus, treated acute schistosomiasis, etc) are representatives of the acute type of degradation. They reveal the main differential ultrastructural features mentioned above as typical of acute degradation $(16,13)$. To further explore on the correlation between time of fibrosis installation and rapidity of fibrosis degradation on one side, and morphological findings on another, an investigation was made on early and late stages of the carbon tetrachloride-induced hepatic fibrosis in rats, after two different periods of drug administration, followed by three periods of observation after drug withdrawal. This study was also considered to, by exploring the subject of acute versus chronic collagen degradation in a well known experimental model of hepatic fibrosis, contribute to the model itself, and stimulate further research on one important topic of hepatic pathology.

\section{Materials and method}

Forty Wistar rats of both sexes, weighing from $150 \mathrm{~g}$ to $300 \mathrm{~g}$, were treated with carbon tetrachloride $\left(\mathrm{CCl}_{4}\right)$, administered by a gastric tube, according to a standardized protocol (19) during eight weeks. After that period of treatment, the animals were separated into two groups of 20 animals each. The administration of the drug was stopped for the first group and continued during four more weeks for the second group. Upon discontinuation of $\mathrm{CCl}_{4}$ administration, in both groups, the animals were submitted to partial hepatectomy (surgical biopsies) 72 hours and two weeks afterwards. Twelve weeks after drug withdrawal, all surviving animals were sacrificed. For the surgical procedures, the animals were anesthetized with ether, the abdomen was shaved and cleaned. Under sterile conditions, the abdomen was opened at the midline and a small portion of the liver (approximately $250 \mathrm{mg}$ ) was removed and the surgical wound sutured. The fragments of the liver, obtained either after surgical biopsy or at necropsy, were submitted to the following procedures:

\section{Histology}

Portions of the liver were fixed in $10 \%$ phosphate buffered formalin and routinely embedded in paraffin. The $5 \mathrm{~m}$-thick-sections were stained with hematoxylin and eosin and the picro-sirius red method for collagen. For semiquantitative evaluation of fibrosis, the Sirius-red stained slides were examined under coding by two independent observers. Fibrosis was registered as mild, (multifocal thin septal and perisinusoidal fibrosis), moderate (disseminated distribution of septae and bands of fibrous tissue) and severe, when cirrhosis was present. Each category was sub-divided into three numerical grades according to its intensity, to facilitate statistical analysis.

\section{Hydroxyproline measurements}

Fragments of the liver, weighing $0.100 \mathrm{mg}-0.200 \mathrm{mg}$, were submitted to the Bergman \& Loxley (6) colorimetric method for the determination of hydroxyprolin content.

\section{Electron microscopy}

Tiny fragments of the liver were immediately fixed in $4 \%$ glutaraldehyde in $0.2 \mathrm{M}$ sodium cacodilate buffer during one hour and post fixed in $2 \%$ osmium tetroxide. After washing and dehydration, the pieces were embedded in Polybed resin. Ultra-thin sections were made with a diamond knife from selected blocks, mounted on copper grids, contrasted with uranyl acetate and lead citrate, and examined in a Zeiss EM-109 electron microscope, under $50 \mathrm{Kv}$.

\section{Morphometry}

The quantitative estimation of fibrous tissue was made on histological liver sections stained with Sirius red. The methodology used was similar to that previously described $(7,8)$. Briefly, the Leica Quantimet Q500MC (Leica Cambridge, Cambridge, UK) Imaging Workstation was used for measuring the fractional surface occupied by fibrosis in a total liver sectional area of $17 \times 10^{6} \mathrm{~mm}^{2}$ for each of the three biological points of every animal from the two groups. 


\section{Statistical analysis}

Variance analysis (Anova) and linear regression (Graphpad Instat) were used to test the differences between the means.

\section{Results}

Animals treated for eight or 12 weeks presented variable degrees of hepatic fibrosis, which tended to gradually disappear following discontinuation of treatment, as can be observed in the Table. In both cases a progressive decrease of fibrosis was noted following drug withdrawal. Such progressive reduction was noted at the different points of observation for each group, being statistically significant by the methods used. Morphometric and biochemical measurements of fibrosis coincided throughout, but semi-quantitative evaluation differed for Group I, by not showing significant differences between the means. Morphometric, semi-quantitative and biochemical estimation of fibrosis failed to demonstrate statistically significant differences between the groups.

Histological and ultrastructural findings were similar for the two groups, and will be described together. Histologically, hepatic fibrosis accompanied by several degrees of liver-cell changes was present in all treated animals. It varied from thin septa to large bands of Siriusred stained fibrous tissue, connecting central canals and portal spaces in various combinations, delimiting hepatocellular nodules of different sizes, frequently exhibiting the complete morphological picture of cirrhosis, as illustrated in Figure 1, which is representative of the main type of evolution in both Groups. Fibrosis seen 72 hours after discontinuation of $\mathrm{CCl}_{4}$ treatment appeared more compact and apparently augmented two weeks later, but definitively became less evident later on. Portal enlargement due to edema, infiltration by mononuclear cells and proliferation of ductal and ductular cells were remarkable 72 hours after treatment, but almost disappeared subsequently. Also, hepatocellular ballooning, macro and micro-vacuolar steatosis and lymphomacrophagic infiltration, especially evident at the centroacinar zone III, 72 hours after treatment, tended to disappear two weeks later. Perisinusoidal fibrosis was frequently found, sometimes forming thin septa along the parenchymal acinar zone III. Such fibrosis was no longer observed in the material from the second biopsy, after discontinuation of the drug. However, some degree of hepatic fibrosis remained in all cases up to the end of experiment.

Electron microscopic changes affecting the interstitial tissues were dominated by focal collagen alterations. In areas where the collagen fibers appeared parallel and packed, focal zones of clarification were noted. In them the fibers and fibrils were fragmented into tiny portions of variable sizes and calibers (Figure 2). Frequently empty circular areas were noted in zones of collagen breakdown. In spite of thorough search, no evidences of internalization or phagocytosis of collagen fragments were detected. Focal electron-dense deposits of a granular or filamentous material were seen replacing collagen fibers (Figure 2B). Sometimes it simulated elastic fibers, but differed from them for being finely granular instead of homogeneous

Semi-quantitative histological grading of fibrosis in the liver, biochemical and Table morphometric data of rats treated for different periods of time with carbon tetrachloride

\begin{tabular}{|c|c|c|c|c|}
\hline Groups & $n$ & $1^{\text {st }}$ hepatectomy & $\begin{array}{c}\text { Mean } \pm \text { SD } \\
2^{\text {nd }} \text { hepatectomy }\end{array}$ & $3^{\text {rd }}$ hepatectomy \\
\hline \multicolumn{5}{|c|}{ Histology (semi-quantitative) } \\
\hline "Early" (I) & 15 & $5.4 \pm 2.9$ & $4.5 \pm 2.4$ & $4.1 \pm 2.4$ \\
\hline "Late" (II) & 12 & $4.9 \pm 3.6$ & $4.2 \pm 2.9$ & $3.5 \pm 2.8^{*}$ \\
\hline \multicolumn{5}{|c|}{ Hydroxyproline $(\mu \mathrm{mol} / \mathrm{g})$} \\
\hline I & 17 & $8.4 \pm 2.9$ & $8.6 \pm 3.7$ & $5.3 \pm 1.4^{*}$ \\
\hline II & 8 & $7.8 \pm 2.6$ & $7.4 \pm 2$ & $5.6 \pm 1.5^{*}$ \\
\hline \multicolumn{5}{|c|}{ Morphometry (\%) } \\
\hline I & 17 & $8 \pm 4.2$ & $7.2 \pm 3.5$ & $5.1 \pm 3^{*}$ \\
\hline II & 9 & $9.3 \pm 6.4$ & $7.7 \pm 3.9$ & $5.6 \pm 4.4^{*}$ \\
\hline
\end{tabular}

${ }^{*} p<0.05$. 

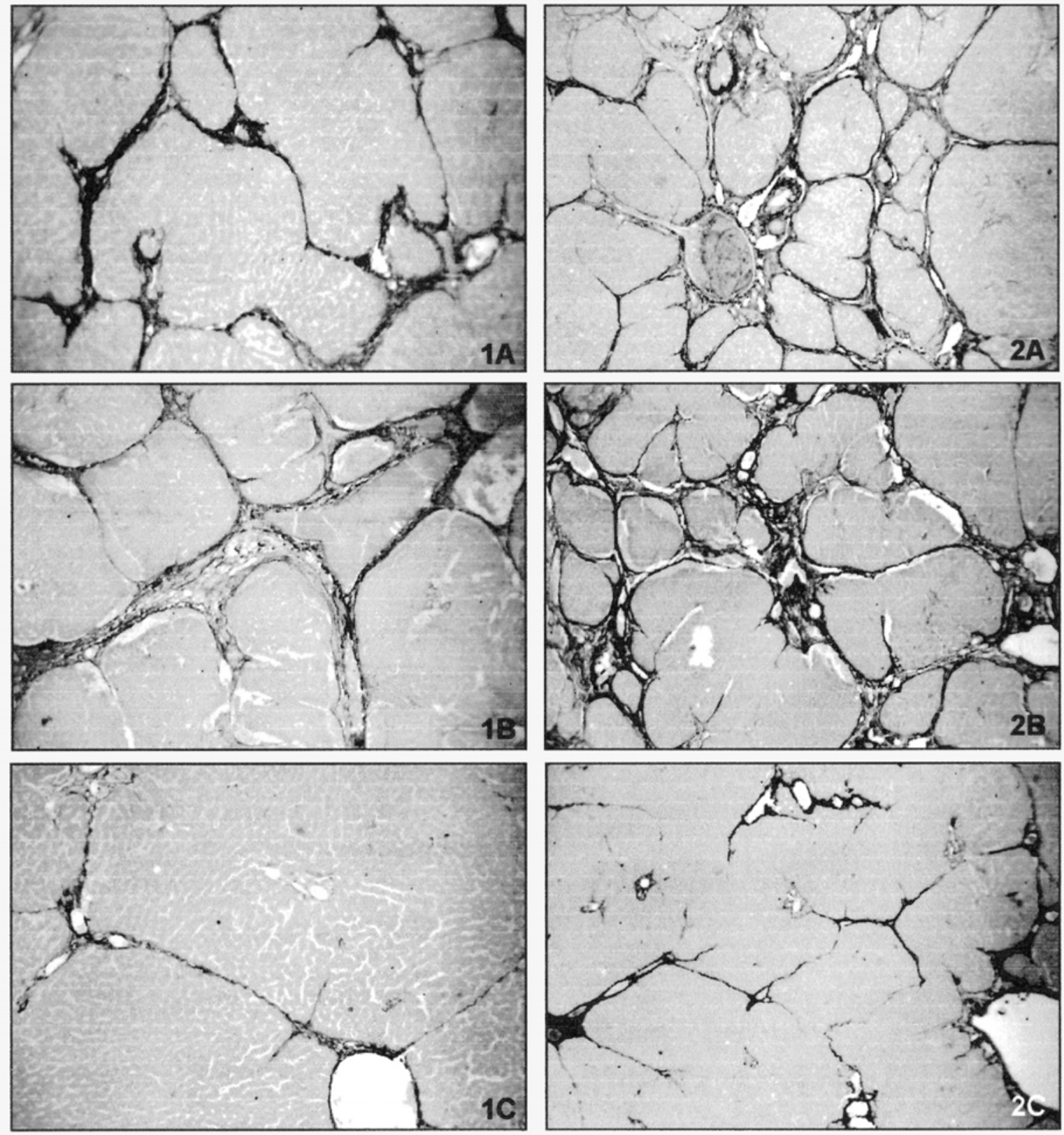

Figure 1 - The picture is representative of the main changes observed in successive specimens taken from the livers of two rats treated with carbon tetrachloride, either for 8 weeks $(1 \mathrm{~A}, 1 \mathrm{~B}$ and $1 \mathrm{C})$ and 12 weeks $(2 \mathrm{~A}, 2 \mathrm{~B}$ and $2 \mathrm{C}$ ), as seen at different periods of time after drug removal: ( $1 \mathrm{~A}$ and $2 \mathrm{~A}: 72$ hours; $1 \mathrm{~B}$ and $2 \mathrm{~B}: 2$ weeks; $1 \mathrm{C}$ and $2 \mathrm{C}: 12$ weeks). In both instances there is a picture of cirrhosis evolving toward mild septal fibrosis at the end of 12 weeks following $\mathrm{CCl}_{4}$ withdrawal. Sirius-red staining, $\times 200$

and compact. That change was more frequently seen in animals treated for 12 weeks, especially when examined 12 weeks after $\mathrm{CCl}_{4}$ treatment. Degenerative changes also appeared in areas containing densely packed collagen fibrils (Figure 3A). Quiescent fibroblasts and myofibroblasts were seen in close proximity to areas of collagen degradation, without a clear relationship other than spatial to the areas of focal collagen degradation (Figure 3B). However, a clear empty space or halo was noted around some connective tissue cells located away from the areas showing focal degradative changes (Figure 3B), suggesting pericellular lysis of the stroma.

Morphometric analysis showed no significant differences between the groups (Table). However, it did demonstrate a progressive decrease in the amount of fibrosis, statistically significant, after discontinuation of $\mathrm{CCl}_{4}$ administration, when the interval points of both groups were considered. 


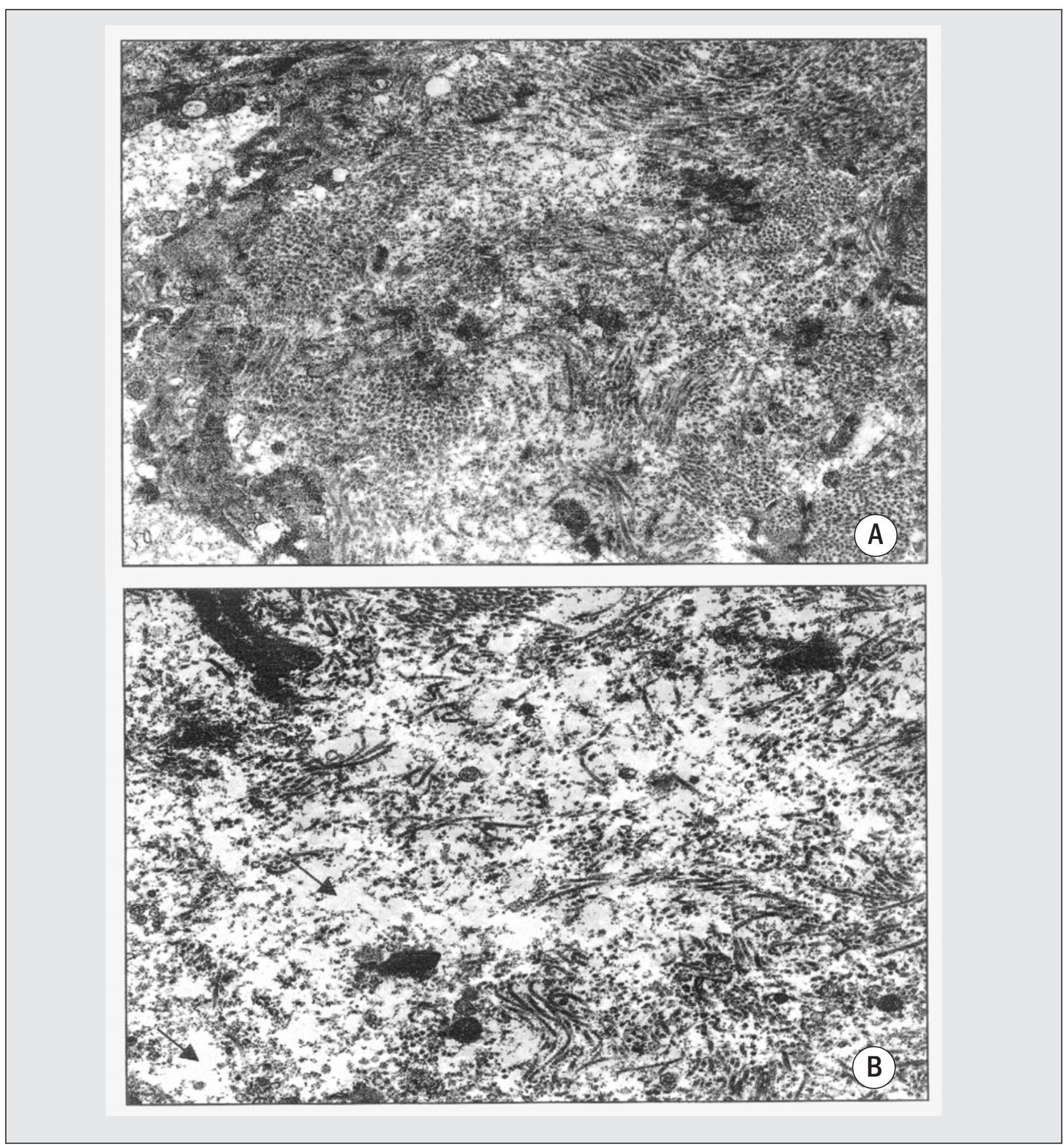

Figure 2 - Focal and extensive fragmentation of collagen fibrils, associated with the presence of dark deposits (focal electron dense change) and clear areas of rarefaction, observed in rats treated with carbon tetrachloride for 12 weeks, 2 weeks (A) and 12 weeks (B) after discontinuation of treatment. Electron micrograph, x 4,400

\section{Discussion}

In the present experiment an attempt was made to produce early and late hepatic fibrosis by means of $\mathrm{CCl}_{4}$ intoxication to rats, in order to comparatively follow its progressive degradation after drug discontinuation. Although the degree of fibrosis, morphologically evaluated by the extension and density of collagen deposition, were higher in rats treated for 12 weeks in comparison to those treated for eight weeks, and more evident the signs of collagen removal in the latter, these differences did not reach statistical significance when quantitative methods were applied. The three methods used for evaluation of fibrosis are adequate and usually yield concordant results. The little discrepancy seen with the semi-quantitative method as compared to the other 

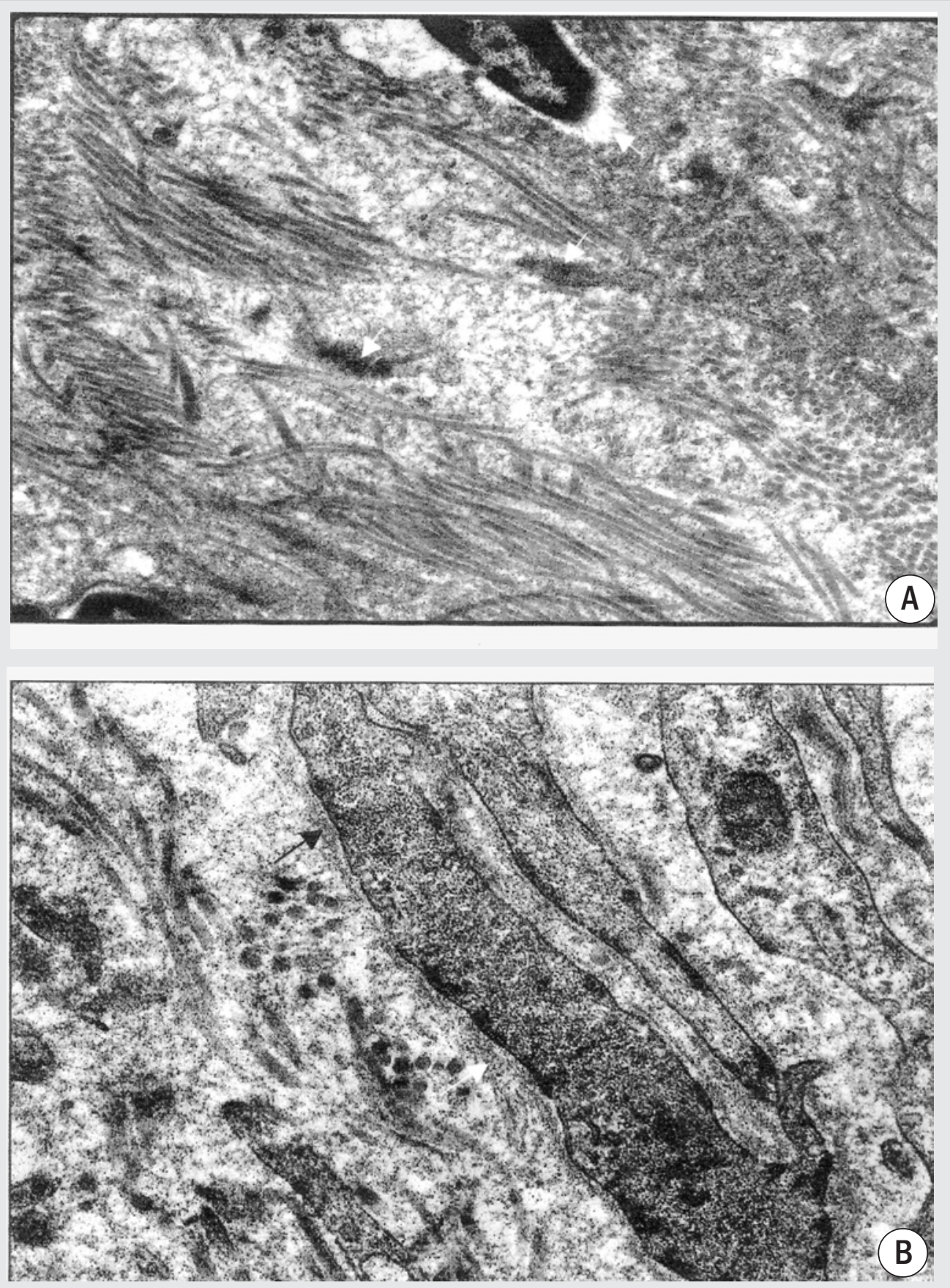

Figure 3 - A - Group II, 2 weeks after treatment. Area of densely packed collagen fibrils showing at the center a clear zone of rarefaction and focal electron-dense granular material (arrow heads). At the top, part of a connective tissue cell exhibiting around it a clear halo of stromal lysis. Electron micrograph, $x$ 7,000; B-Group I, 2 weeks after treatment. Area of fragmentation of collagen fibrils in the presence of myofibroblasts, which exhibit sub-membranar stress fibers and peri-cellular non-fibrilar collagen (arrows). Electron micrograph, $x 7,000$

methods, by showing no statistically significant differences between the examination points in Group I, is to be expected within the limitations of such methodology. Previously, our group obtained concordant results with the three methods $(8,20)$. Ultrastructural findings were, likewise, essentially similar in both groups and at their point intervals. The overall picture was consistent with the process of chronic collagen degradation, as seen in other experimental models (4, $11)$ and in long standing fibrosis of man $(1,5,12)$.

The reasons why no essential differences were found in the quantitative and qualitative features of collagen 
degradation in the present experiments were rather unexpected. Probably the $\mathrm{CCl}_{4}$-induced hepatic fibrosis in the rat model, especially because of its association with cirrhosis, is not adequate for the study of early collagen degradation. The effects of $\mathrm{CCl}_{4}$ administration upon the liver is long lasting after drug removal, probably inhibiting the immediate action of the factors responsible for a more rapid collagen resorption, when the causal agent is suddenly removed. Persistence of collagen in tissue favors the process of intra molecular and inter molecular crossing link, turning the fibers more resistant to enzymatic digestion (10). In models showing acute collagen degradation, it appears that the stimulus for fibrogenesis ceases rather suddenly, given rise to the characteristic degradative changes $(3,11,13,16)$. That did not seem to occur in $\mathrm{CCl}_{4}$-treated animals.

The change in hepatic structure during cirrhosis is a point of considerable importance. Further studies may be necessary to evaluate how chronic damage to an organ or structure may interfere with collagen degradation, even when the cause of fibrosis was completely removed. Cirrhosis is accompanied by marked subversion of the hepatic structure, especially of its vascular component (18). In this regard it differs from advanced hepatic schistosomiasis, which presents marked portal fibrosis, but maintains normal parenchymal structure. It is interesting to note that clinical, ultrasonographic and pathological studies have demonstrated almost total reversal of the liver pathology in hepatosplenic schistosomiasis patients following specific treatment of the parasitosis $(2,9,14)$. On the other hand, hepatic cirrhosis has for long time been considered irreversible, although some data on the contrary are now on record.

Recently, Wanless et al. (21) made a detailed description of the histological changes indicative of regression of human cirrhosis. They called attention to a series of findings comprising the "hepatic repair complex" observed in a series of 52 livers removed at transplantation. The majority of the morphological parameters they considered as representative of hepatic repair could also be identified in the present material, confirming that the model of $\mathrm{CCl}_{4}{ }^{-}$ induced hepatic fibrosis, so largely used to study fibrogenesis, can with advantage be utilized to investigate the evolution and morphology of fibrolysis.

\section{References}

I. Andrade, Z.A. Morphological features of collagen degradation in advanced hepatic schistosomiasis of man. Mem. Inst. Oswaldo Cruz, 87(Suppl. IV): 129-38, 1992.

2. Andrade, Z.A. Extracellular matrix degradation in parasitic diseases. Braz. J. Med. Biol. Res., 27: 2273-81, 1994.

3. Andrade, Z.A \& Grimaud, J.A. Evolution of the schistosomal hepatic lesions in mice after curative chemotherapy. Am.J. Pathol., 124:59-65, 1986.

4. Andrade, Z.A. \& Grimaud, J.A. Morphology of chronic collagen resorption. (A study on the late stages of schistosomal granuloma involution). Am. J. Pathol., 132: 389-99, 1988.

5. Andrade, Z.A. et al. Hepatic connective tissue changes in hepatosplenic schistosomiasis. Hum. Pathol., 23: 566-73, 1992.

6. Bergman, I. \& Loxley, R. Improved and simplified methods for the spectrophotometric determination of hydroxyproline. Annals of Chemistry, 35: 1961-65, 1963.

7. Barbosa Jr, A. A. Morphological computer-assisted quantitative estimation of stained fibrous tissue in liver sections: applications in diagnosis and experimental research.J. Bras. Patol., 37: | 97-200, 200 I.

8. Coutinho, E.M, et al. Pathogenesis of schistosomal "pipestem" fibrosis (A Low-protein diet inhibits the development of "pipestem" fibrosis in mice). Internat. I. Exp. Patho., 78: 337 42, 1997.
9. Dietze, R.S. \& Prata, A. Rate of reversion of hepatosplenic schistosomiasis after specific chemotherapy. Rev. Soc. Brás, Méd.Trop., 19:69-73. 1986.

10. Emonard, H. \& Grimaud, J.A. Active and latent collagenase activity during reversal of hepatic fibrosis in murine schistosomiasis. Hepatology, 10:77-83, 1989.

I I. Freitas, L.A.R. et al. Morphological aspects of early and late collagen degradation in granulation tissue. Exper. Toxicol. Pathol., 44: I28-33, 1992.

12. Gomez, D.E. et al. Expression of metalloproteinases (MMP-I and MMP-2) and their inhibitors (TIMP-I and TIMP-2) in schistosomal portal fibrosis. Am. J. Trop. Med. \& Hyg., 61:913, 1999.

13. Henell, F.; Bricsson, J.L.E. \& Glaumann, H. An electron microscopic study of the post partum involution of the rat uterus: with a note on apparent crinophagy of collagen. Virch.Arch. B. Cell Pathol., 42: 27I-87, 1983.

14. Homeida, M.A. et al. Morbidity associated with Schistosoma mansoni infection as determined by ultrasound: a study in Gezira, Sudan. Am. J. Trop. Med. \& Hyg., 39: 196-201, 1988.

15. Murphy, G. \& Reynolds, J.J. Extra cellular matrix degradation. In: Boyce P.M. \& Steinmann, B. (eds.) Connective tissue and its heritable disorders. New York: Wiley-Liss Inc., 1993, p. $287-316$. 
16. Perez-Tamayo, R. Collagen resorption in carrageenin granulomas. II. Ultrastructure of collagen resorption. Lab. Invest., 22: |42-57, 1970.

17. Perez-Tamayo, R. Pathology of collagen degradation: a review. Am. J. Pathol., 92: 509-66, 1978.

18. Popper, H. Pathologic aspects of cirrhosis. Am. J. Pathol., 87: 228-58, 1977.
19. Rosa, H. et al. Controlled production of cirrhosis in the rats liver. Arq. Gastroenterol., 28: 39, 1991.

20. Souza, M.M. et al. Hepatic capillariasis in rats: a new model for testing anti-fibrosis drugs . Braz.J. Med. \& Biol. Res., 33: I 329-34, 2000.

2I.Wanless, I.R.; Nakashima, E. \& Sherman, M. Regression of human cirrhosis. Morphologic features and the genesis of incomplete septal cirrhosis. Arch. Pathol. \& Lab. Med., I 24: I 599-607, 2000. 